\title{
A Quantitative Systems Approach Reveals Dynamic Control of tRNA Modifications during Cellular Stress
}

\author{
Clement T. Y. Chan ${ }^{1,2}$, Madhu Dyavaiah ${ }^{3}$, Michael S. DeMott ${ }^{1}$, Koli Taghizadeh ${ }^{4}$, Peter C. Dedon ${ }^{1,4 *}$, \\ Thomas J. Begley ${ }^{3 *}$
}

1 Department of Biological Engineering, Massachusetts Institute of Technology, Cambridge, Massachusetts, United States of America, 2 Department of Chemistry, Massachusetts Institute of Technology, Cambridge, Massachusetts, United States of America, 3 Department of Biomedical Sciences, Gen*NY*sis Center for Excellence in Cancer Genomics, University at Albany, State University of New York, Rensselaer, New York, United States of America, $\mathbf{4}$ Center for Environmental Health Sciences, Massachusetts Institute of Technology, Cambridge, Massachusetts, United States of America

\begin{abstract}
Decades of study have revealed more than 100 ribonucleoside structures incorporated as post-transcriptional modifications mainly in tRNA and rRNA, yet the larger functional dynamics of this conserved system are unclear. To this end, we developed a highly precise mass spectrometric method to quantify tRNA modifications in Saccharomyces cerevisiae. Our approach revealed several novel biosynthetic pathways for RNA modifications and led to the discovery of signature changes in the spectrum of tRNA modifications in the damage response to mechanistically different toxicants. This is illustrated with the RNA modifications $\mathrm{Cm}, \mathrm{m}^{5} \mathrm{C}$, and $\mathrm{m}_{2}^{2} \mathrm{G}$, which increase following hydrogen peroxide exposure but decrease or are unaffected by exposure to methylmethane sulfonate, arsenite, and hypochlorite. Cytotoxic hypersensitivity to hydrogen peroxide is conferred by loss of enzymes catalyzing the formation of $\mathrm{Cm}, \mathrm{m}^{5} \mathrm{C}$, and $\mathrm{m}^{2}{ }_{2} \mathrm{G}$, which demonstrates that tRNA modifications are critical features of the cellular stress response. The results of our study support a general model of dynamic control of tRNA modifications in cellular response pathways and add to the growing repertoire of mechanisms controlling translational responses in cells.
\end{abstract}

Citation: Chan CTY, Dyavaiah M, DeMott MS, Taghizadeh K, Dedon PC, et al. (2010) A Quantitative Systems Approach Reveals Dynamic Control of tRNA Modifications during Cellular Stress. PLoS Genet 6(12): e1001247. doi:10.1371/journal.pgen.1001247

Editor: Nancy Maizels, University of Washington, United States of America

Received August 16, 2010; Accepted November 15, 2010; Published December 16, 2010

Copyright: (c) 2010 Chan et al. This is an open-access article distributed under the terms of the Creative Commons Attribution License, which permits unrestricted use, distribution, and reproduction in any medium, provided the original author and source are credited.

Funding: This work was supported by the National Institute of Environmental Health Sciences (ES002109, ES017010, and ES015037; http://www.niehs.nih.gov/), the National Cancer Institute (CA026731; http://www.cancer.gov/), the National Center for Research Resources (RR023783; http://www.ncrr.nih.gov/), the MIT Westaway Fund, the Merck-CSBI Graduate Fellowship Program, and the Singapore-MIT Alliance for Research and Technology (http://web.mit.edu/SMART/). The funders had no role in study design, data collection and analysis, decision to publish, or preparation of the manuscript.

Competing Interests: The authors have declared that no competing interests exist.

*E-mail: pcdedon@mit.edu (PCD); tbegley@albany.edu (TJB)

\section{Introduction}

The complexity of the transfer RNA (tRNA) system confers great potential for its use in cellular regulatory programs. There are hundreds of tRNA-encoding genes in S. cerevisiae and human genomes, with extensive post-transcriptional processing that includes enzyme-mediated ribonucleoside modifications [1]. Considering both tRNA and ribosomal RNA (rRNA), there are more than 100 known ribonucleoside modifications across all organisms in addition to the canonical adenosine, guanosine, cytidine and uridine [2,3]. In general, tRNA modifications enhance ribosome binding affinity, reduce misreading and modulate frame-shifting, all of which affect the rate and fidelity of translation [4-7]. However, information about the higher-level biological function of ribonucleoside modifications has only recently begun to emerge. We have approached this problem with a systems-level analysis of changes in the spectrum of ribonucleosides in tRNA as a function of cell stress, which has revealed novel insights into the biosynthesis of tRNA modifications and their role in cellular responses.

Emerging evidence points to a critical role for tRNA and rRNA modifications in cellular responses to stimuli, with evidence for a role in tRNA stability [8,9], cellular stress responses [10-12] and cell growth [13]. We recently used high-throughput screens and targeted studies to show that the tRNA methyltransferase 9 (Trm9) modulates the toxicity of methylmethanesulfonate (MMS) in $S$. cerevisiae $[11,14]$. This is similar to the observed role of Trm9 in modulating the toxicity of ionizing radiation [15] and of Trm4 in promoting viability after methylation damage [14,16]. Trm9 catalyzes the methyl esterification of the uracil-based $\mathrm{cm}^{5} \mathrm{U}$ and $\mathrm{cm}^{5} \mathrm{~s}^{2} \mathrm{U}$ to $\mathrm{mcm}^{5} \mathrm{U}$ and $\mathrm{mcm}^{5} \mathrm{~s}^{2} \mathrm{U}$, respectively, at the wobble bases of tRNA ${ }^{\text {UCU }}$-ARG and tRNA ${ }^{\text {CGU }}$-GLU, among others [17]. These wobble base modifications in the tRNA enhance binding of the anticodon with specific codons in mixed codon boxes [18]. Codon-specific reporter assays and genome-wide searches revealed that Trm9-catalyzed tRNA modifications enhanced the translation of AGA- and GAA-rich transcripts that functionally mapped to processes associated with protein synthesis, metabolism and stress signalling [11]. The resulting model proposes that specific codons will be more efficiently translated by anticodons containing the Trm9-modified nucleoside and that tRNA modifications can dynamically change in response to stress.

To assess the dynamic nature of tRNA modifications proposed by this model, we developed a systems-oriented approach using liquid chromatography-coupled, tandem quadrupole mass spectrometry (LC-MS/MS) to quantify the full set of tRNA modifications in an organism. Mass spectrometry-based methods have recently emerged as powerful tools for identifying and 


\section{Author Summary}

While the genetic code in DNA is read from four nucleobase structures, there are more than 100 ribonucleoside structures incorporated as post-transcriptional modifications mainly in tRNA and rRNA. These structures and their biosynthetic machinery are highly conserved, with 20-30 present in any one organism, yet the larger biological function of the modifications has eluded understanding. To this end, we developed a sensitive and precise mass spectrometric method to quantify 23 of the 25 ribonucleosides in the model eukaryotic yeast, Saccharomyces cerevisiae. We discovered that the spectrum of ribonucleosides shifts predictably when the cells are exposed to different toxic chemical stimulants, with these signature changes in the spectrum serving as part of the cellular survival response to these exposures. The method also revealed novel enzymatic pathways for the synthesis of several modified ribonucleosides. These results suggest a dynamic reprogramming of the tRNA and rRNA modifications during cellular responses to stimuli, with corresponding modifications working as part of a larger mechanism of translational control during the cellular stress response.

quantifying RNA modifications [19,20]. We applied such an approach to quantify changes in the spectrum of tRNA modifications in yeast exposed to four mechanistically dissimilar toxicants. Multivariate statistical analysis of the data reveals dynamic shifts in the population of RNA modifications as part of the response to damage, with signature changes for each agent and dose. Further, analysis of yeast mutants lacking specific modification enzymes revealed novel biosynthetic pathways and compensatory or cooperative shifts in the levels of other modifications.

\section{Results/Discussion}

\section{Development of an LC-MS/MS method to quantify modified ribonucleosides}

As shown in Figure 1, we developed an LG-MS/MS method capable of quantifying 23 of the $\sim 25$ known ribonucleoside modifications in cytoplasmic tRNA in $S$. cerevisiae [2,3]. The method begins with isolation of small RNA species $(<200 \mathrm{nt})$ and quantification of the tRNA content $(\sim 80-90 \%$ of small RNA species). Individual ribonucleosides in enzymatic hydrolysates of tRNA were resolved by HPLC and identified by high mass accuracy mass spectrometry, by fragmentation patterns with collision-induced dissociation (CID) and by comparison to chemical standards. Each ribonucleoside was subsequently quantified by pre-determined molecular transitions during CID in the LC-MS/MS system. We were able to quantify 23 of the 25 tRNA modifications in yeast, with $2^{\prime}$-O-ribosyladenosine phosphate $(\operatorname{Ar}(\mathrm{p}))$ not detected in positive ion mode, possibly due to the negatively charged phosphate, and only tentative identification of $\mathrm{ncm}{ }^{5} \mathrm{Um}$ by CID due to weak signal intensities.

A critical feature of our approach is quantitative rigor given the need for highly precise measurement of even small changes in the relative quantities of ribonucleosides. To this end, we used an Agilent Bioanalyzer (microfluidics-based sizing and quantification against an internal standard) for quantification of total tRNA species in the mixture of small RNA $(85 \pm 5 \%, \mathrm{~N}=39)$ and an internal standard $\left(\left[{ }^{15} \mathrm{~N}_{5}\right]-2^{\prime}\right.$-deoxyriboadenosine $)$ to minimize variation in the levels of the individual ribonucleosides. One caveat here is low-level contamination (a few percent) with $5 \mathrm{~S}$

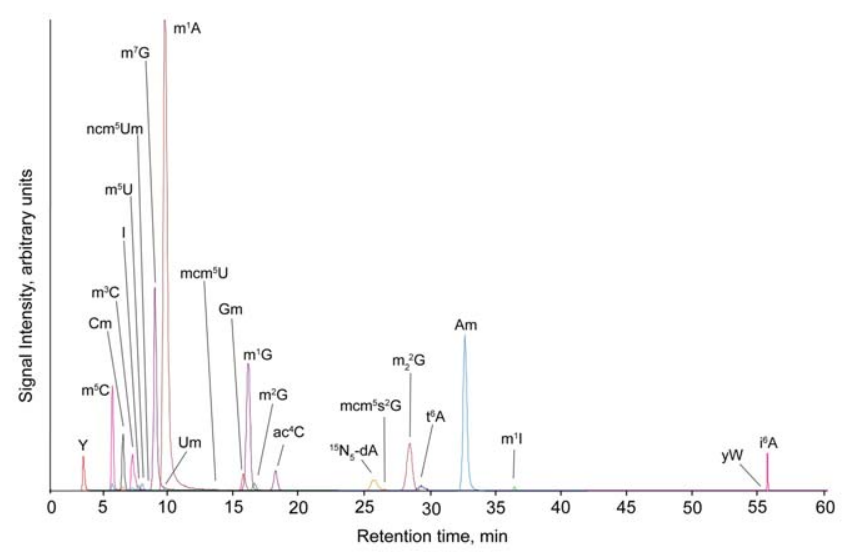

Figure 1. Total ion chromatogram from LC-MS/MS analysis of yeast tRNA ribonucleosides, as described in Materials and Methods.

doi:10.1371/journal.pgen.1001247.g001

rRNA that also contains ribonucleoside modifications. We were able to obtain highly reproducible data for the signal intensity associated with each ribonucleoside (see Figure S1 for linearity of signal intensity for the 23 ribonucleosides). Multiple reaction monitoring (MRM) mode yielded no detectable background signal in the absence of tRNA hydrolysates except for $i^{6} \mathrm{~A}(9 \pm 2 \%)$. The method proved to be highly precise: $3 \pm 1 \%$ intra-day variance in average signal intensity and $12 \pm 10 \%$ inter-day variance in average fold-change values for each ribonucleoside in treated and untreated cells (294 analyses in three biological replicates over several weeks).

Analysis of tRNA from wild type cells revealed a three-log range of signal intensity, with $\mathrm{I}$ and $\mathrm{ac}^{4} \mathrm{C}$ producing the highest intensity and $\mathrm{ncm}^{5} \mathrm{Um}$ the lowest (Figure 1). In general, modifications can be categorized in high ( $\mathrm{I}, \mathrm{ac}^{4} \mathrm{C}, \mathrm{m}^{1} \mathrm{~A}, \mathrm{~m}^{2}{ }_{2} \mathrm{G}, \mathrm{Am}, \mathrm{Y}$ ), medium $\left(\mathrm{Cm}, \mathrm{m}^{5} \mathrm{C}, \mathrm{Gm}, \mathrm{m}^{1} \mathrm{G}, \mathrm{t}^{6} \mathrm{~A}, \mathrm{~m}^{7} \mathrm{G}, \mathrm{m}^{2} \mathrm{G}, \mathrm{m}^{3} \mathrm{C}, \mathrm{i}^{6} \mathrm{~A}\right)$ and low signal intensities $\left(\mathrm{m}^{1} \mathrm{I}, \mathrm{D}, \mathrm{m}^{5} \mathrm{U}, \mathrm{ncm}{ }^{5} \mathrm{Um}, \mathrm{mcm}^{5} \mathrm{U}, \mathrm{mcm}^{5} \mathrm{~s}^{2} \mathrm{U}, \mathrm{Um}, \mathrm{yW}\right.$, $n \mathrm{~nm}^{5} \mathrm{U}$ ), with signal intensity reflecting both the abundance and mass spectrometric sensitivity for each ribonucleoside.

\section{Yeast exposure parameters}

To quantify the dynamics of tRNA modifications in cellular responses, we selected four well studied chemicals that possess distinct mechanisms of toxicity: MMS, hydrogen peroxide $\left(\mathrm{H}_{2} \mathrm{O}_{2}\right)$, sodium arsenite $\left(\mathrm{NaAsO}_{2}\right)$, and sodium hypochlorite $\left(\mathrm{NaOCl}, \mathrm{pK}_{\mathrm{a}}\right.$ 7.5; ref. [21]). The behavior of yeast upon exposure to MMS, $\mathrm{NaAsO}_{2}$ and $\mathrm{H}_{2} \mathrm{O}_{2}$ has been extensively studied in terms of transcriptional response and cytotoxicity phenotyping [11,22,23]. We also chose $\mathrm{NaOCl}$ since it produces an oxidative stress distinct from that of $\mathrm{H}_{2} \mathrm{O}_{2}$ and could thus affect the tRNA modification spectrum differently. We then performed cytotoxicity doseresponse studies in $S$. cerevisiae exposed to agents (Figure S2), choosing concentrations (Figure 2) that produced $\sim 20 \%, 50 \%$ and $80 \%$ cytotoxicity to ensure a common phenotypic endpoint for comparison.

One important issue with the methylating agent, MMS, was the possibility that changes in methyl-based modifications in tRNA could be due to both enzymatic methylation and direct chemical methylation. Literature precedent indicates that MMS reacts with DNA to form adducts mainly at guanine $\mathrm{N}^{7}(68 \%)$, adenine $\mathrm{N}^{1}$ $(18 \%)$ and cytosine $\mathrm{N}^{3}(10 \%)$ [24,25]. To address the extent of direct methylation of RNA by MMS, control studies were performed and revealed that direct alkylation by MMS contributes 


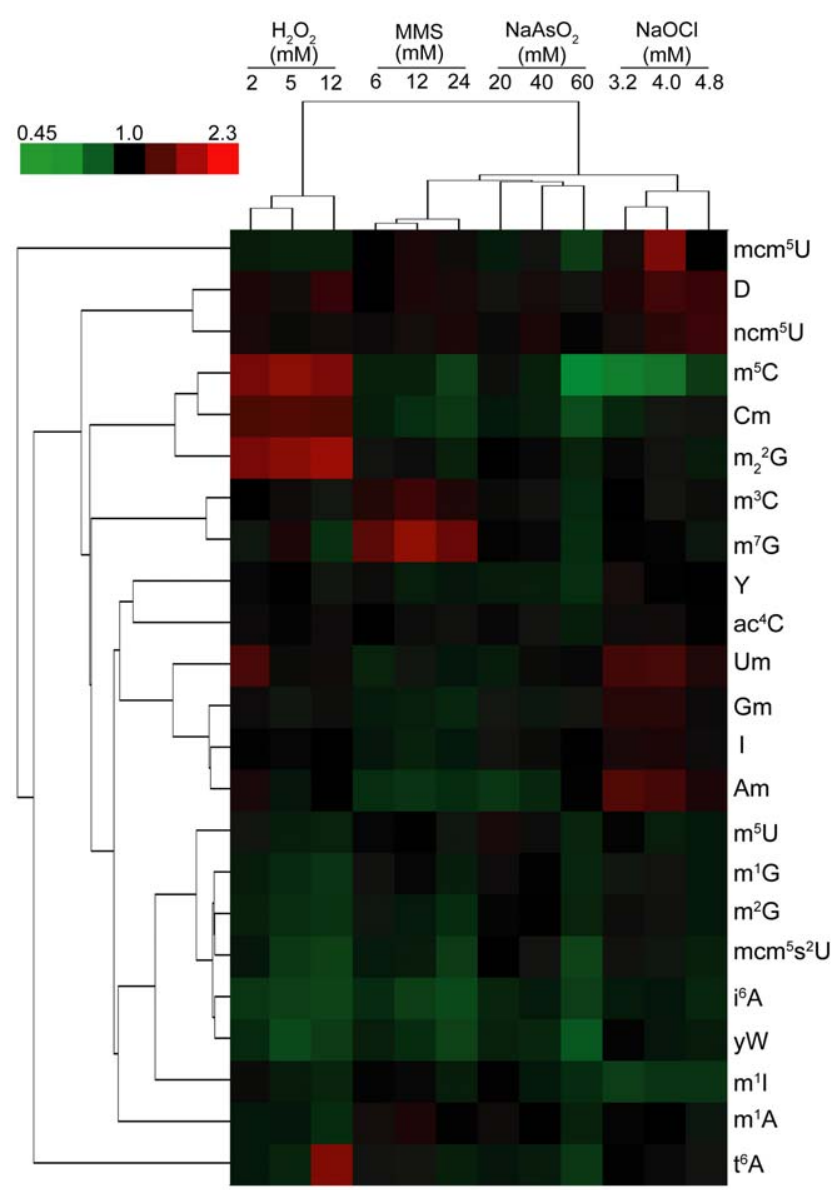

Figure 2. Hierarchical cluster analysis of toxicant-induced changes in tRNA modification spectra in wild-type yeast exposed to concentrations of $\mathrm{MMS}, \mathrm{H}_{2} \mathrm{O}_{2}, \mathrm{NaOCl}$, and $\mathrm{NaAsO}_{2}$ producing $\mathbf{2 0} \%, 50 \%$, and $80 \%$ cytotoxicity. LC-MS/MS quantification of ribonucleosides was performed as described in Materials and Methods and data expressed as fold-change relative to unexposed controls (Table S2), with hierarchical cluster analysis performed on mean-centered data. The top-left color bar indicates the range of foldchange values.

doi:10.1371/journal.pgen.1001247.g002

$<25 \%$ to the cellular burden of $\mathrm{m}^{7} \mathrm{G}$ in small RNA, with the bulk of $\mathrm{m}^{7} \mathrm{G}$ arising by enzymatic methylation of tRNA (Figure S3). No other agent affected tRNA modifications in this manner, with changes in the relative quantities of the modifications resulting from alterations in biosynthesis, tRNA gene transcription or tRNA degradation.

\section{Reprogramming tRNA modifications during the stress response}

With exposure and analytical parameters established, we tested the hypothesis that the spectrum of tRNA modifications would dynamically change as a function of the $S$. cerevisiae stress response. In addition, we predicted that these changes would serve as biomarkers of each exposure. Cells were exposed to three concentrations of each chemical and 23 tRNA modifications were quantified by LC-MS/MS, with the results shown in Tables S1 and $\mathrm{S} 2$, the latter as the ratio of treated to control signal intensities. A crude analysis of the data shows fold-changes ranging from 0.2 to 4 , with $25 \%$ and $36 \%$ of the exposure data significantly different from control values by Student's t-test at $\mathrm{p}<0.05$ and $\mathrm{p}<0.1$, respectively (Table S2). These results point to the non-random and regulated nature of the exposure-induced changes in the levels of the tRNA modifications.

Multivariate statistical analyses revealed important patterns or signatures in the toxicant-induced changes in tRNA modifications. As shown in Figure 2, hierarchical clustering distinguished both agent- and dose-specific changes in the modification spectra, with unique patterns of increase and decrease apparent in all cases. $\mathrm{H}_{2} \mathrm{O}_{2}$ consistently increased the levels of $\mathrm{m}^{5} \mathrm{C}, \mathrm{Cm}$ and $\mathrm{m}_{2}{ }^{2} \mathrm{G}$ and, at the highest concentration, $\mathrm{t}^{6} \mathrm{~A}$, with dose-dependent decreases in $\mathrm{m}^{5} \mathrm{U}, \mathrm{m}^{1} \mathrm{G}, \mathrm{m}^{2} \mathrm{G}, \mathrm{mcm}^{5} \mathrm{~s}^{2} \mathrm{U}, \mathrm{i}^{6} \mathrm{~A}, \mathrm{yW}$ and $\mathrm{m}^{1} \mathrm{~A}$. MMS consistently increased the level of $\mathrm{m}^{7} \mathrm{G}$, and decreased $\mathrm{Am}$, $\mathrm{m}^{5} \mathrm{C}, \mathrm{Cm}, \mathrm{mcm}^{5} \mathrm{~s}^{2} \mathrm{U}, \mathrm{i}^{6} \mathrm{~A}$, and $\mathrm{yW}$. $\mathrm{NaAsO}_{2}$ caused only decreases in modification levels at the highest concentration, most notably for $\mathrm{mcm}^{5} \mathrm{U}, \mathrm{m}^{3} \mathrm{C}, \mathrm{m}^{7} \mathrm{G}, \mathrm{mcm}^{5} \mathrm{~s}^{2} \mathrm{U}, \mathrm{i}^{6} \mathrm{~A}, \mathrm{yW}, \mathrm{m}^{5} \mathrm{C}$, and $\mathrm{Cm}$. Interestingly, the dose-response for $\mathrm{NaOCl}$ showed an inverse correlation between concentration and increased levels of $\mathrm{Am}$ and $\mathrm{Um}$ and decreased levels of $\mathrm{m}^{5} \mathrm{C}$. Given the reproducibility of the data, the changes in tRNA modification spectra can be considered signature biomarkers of exposure for these four classes of chemical stressor.

Principal component analysis (PCA) creates a model that reduces the complexity of a data set by identifying hidden correlations (the principal components) comprised of weighted, linear combinations of the original variables, with the first principal component (P1) accounting for the largest portion of the variation of the data and so on. The results of PCA of the dataset of nucleoside fold-change values (Table S2) are shown in Figure 3. With $88 \%$ of the variability expressed in the first 3 principal components $(56 \%, 22 \%$ and $10 \%$, respectively), individual agents contributed variance to each as shown in Table S3, with $\mathrm{H}_{2} \mathrm{O}_{2}$ contributing $74 \%$ in $\mathrm{P} 1$, MMS and $\mathrm{NaOCl}$ each contributing $>40 \%$ in $\mathrm{P} 2$ and $\mathrm{NaAsO}_{2}$ contributing $53 \%$ in $\mathrm{P} 3$. The scores plots (Figure 3A, 3C) clearly distinguish the four agents, with $\mathrm{H}_{2} \mathrm{O}_{2}$-induced changes as the major determinant of $\mathrm{Pl}$ and with MMS, $\mathrm{NaOCl}$ and $\mathrm{NaAsO}_{2}$ distinguished best in $\mathrm{P} 2$. While $\mathrm{H}_{2} \mathrm{O}_{2}$ and $\mathrm{NaOCl}$ are negatively correlated in $\mathrm{P} 1$, they are more closely grouped in $\mathrm{P} 2$ and $\mathrm{P}$, which suggests that the changes in tRNA modifications reflect both common and unique facets of the toxic mechanism of each agent. For example, $\mathrm{H}_{2} \mathrm{O}_{2}$ and $\mathrm{NaOCl}$ are both oxidizing agents, but $\mathrm{H}_{2} \mathrm{O}_{2}$ generates hydroxyl radicals by Fenton chemistry while the protonated form of $\mathrm{NaOCl}$ yields hydroxyl radicals, chloramines and singlet oxygen [26-29]. Similarly, MMS and $\mathrm{NaAsO}_{2}$ are negatively correlated in P3 and more positively correlated in $\mathrm{P} 2$, with the latter consistent with recent evidence for alkylation-like adduction of arsenic to DNA and proteins following its metabolism [30,31]. This would also explain the negative correlation of $\mathrm{NaAsO}_{2}$ and $\mathrm{H}_{2} \mathrm{O}_{2}$ in $\mathrm{Pl}$, while the recognized oxidative stress caused by arsenite [32] is consistent with a positive correlation between $\mathrm{NaAsO}_{2}$ and $\mathrm{H}_{2} \mathrm{O}_{2}$ in $\mathrm{P}$ 2.

Both PCA (Figure 3B, 3D) and cluster analysis (Figure 2) revealed that $\mathrm{m}^{5} \mathrm{C}, \mathrm{m}_{2}{ }^{2} \mathrm{G}, \mathrm{Cm}$ and $\mathrm{t}^{6} \mathrm{~A}$ are major features of the $\mathrm{H}_{2} \mathrm{O}_{2}$ response, while $\mathrm{m}^{1} \mathrm{~A}, \mathrm{~m}^{3} \mathrm{C}$ and $\mathrm{m}^{7} \mathrm{G}$ were associated with MMS. Increases in Gm, Um, I and Am were responsible for the variance induced by $\mathrm{NaOCl}$, which is consistent with the inversely related doses and levels for Am and Um observed in cluster analysis. $\mathrm{NaAsO}_{2}$ was poorly distinguished in $\mathrm{P} 2$, with only $\mathrm{m}^{2} \mathrm{G}$ accounting for variance only at the highest concentrations (Figure 2).

\section{tRNA modification biosynthetic pathways are critical to} the stress response

The observation of toxicant- and dose-dependent changes in the levels of the 23 tRNA modifications is consistent with a model in 

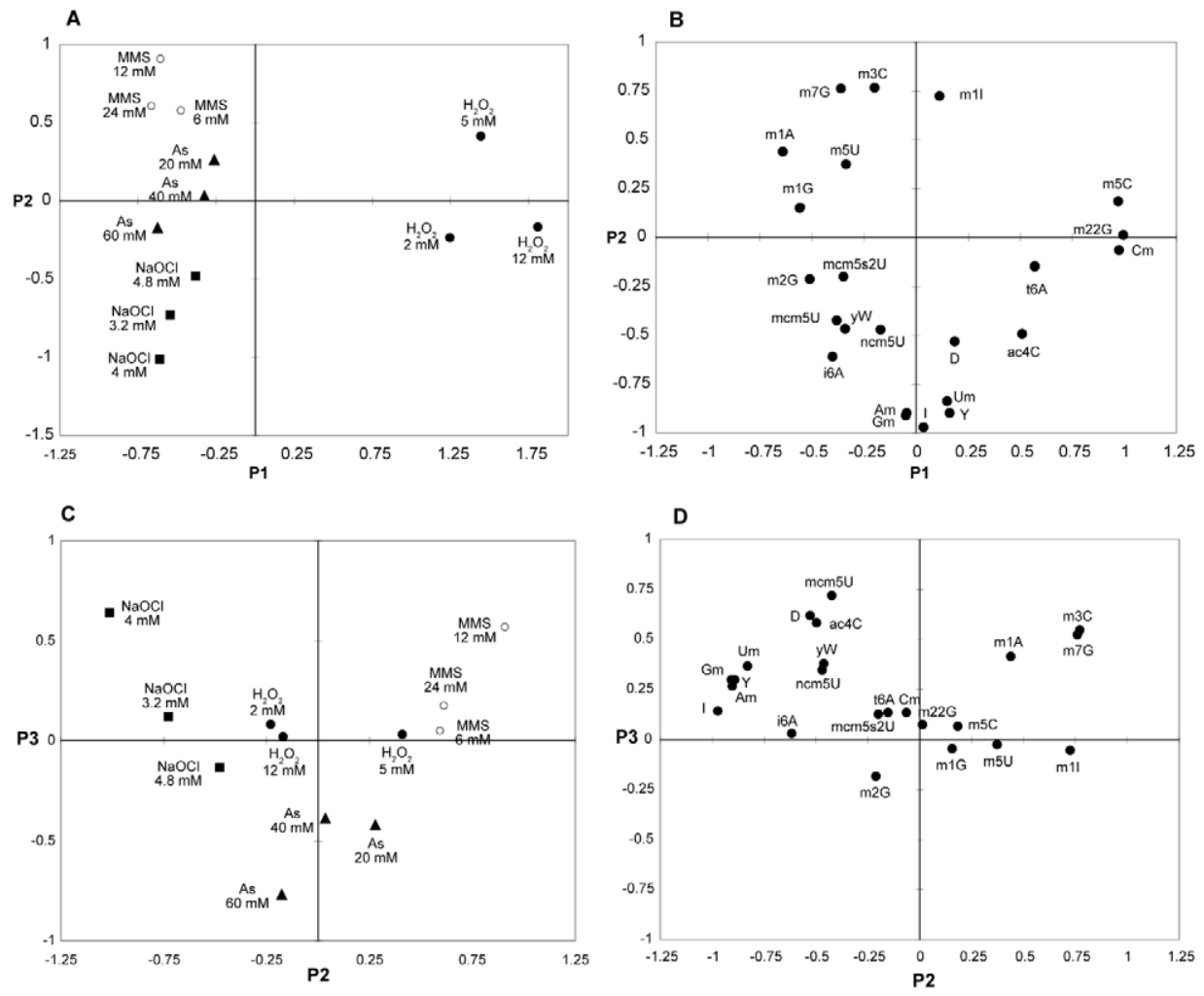

Figure 3. Principal component analysis (PCA) of changes in the levels of tRNA modifications caused by exposure to $\mathrm{MMS} \mathrm{H}_{2} \mathrm{O}_{2}$, $\mathrm{NaOCl}$, and $\mathrm{NaAsO}_{2}$. Toxicant-induced changes in the relative quantities of 23 tRNA ribonucleoside modifications (Table S2) were subjected to PCA following mean centering and normalization of the fold-change data. doi:10.1371/journal.pgen.1001247.g003

which cells respond to toxicant exposure by modifying tRNA structure to enhance the synthesis of proteins critical to cell survival, as has been proposed in our earlier work with yeast exposure to MMS [11]. In this case, the conversion of $\mathrm{cm}^{5} \mathrm{U}$ to $\mathrm{mcm}^{5} \mathrm{U}$ by $\mathrm{Trm} 9$ was found to be critical for surviving MMS exposure [11]. To define the roles of specific tRNA modifications in the toxicant response, cytotoxicity phenotypic analyses were performed with yeast mutants lacking each of $13 \mathrm{trm}$ tRNA methyltransferase genes and 3 other types of RNA modification biosynthetic genes. As shown in Figure 4, heightened sensitivity to $\mathrm{H}_{2} \mathrm{O}_{2}$ was observed in mutants lacking Trm4 and Trm7, which catalyze formation of two modifications elevated by $\mathrm{H}_{2} \mathrm{O}_{2}$ exposure: $\mathrm{m}^{5} \mathrm{C}$ and $\mathrm{Cm}$, respectively [33,34]. The simple explanation is that the increase in a specific tRNA modification is needed to promote an efficient stress response. However, $\mathrm{m}_{2}^{2} \mathrm{G}$ was also elevated by $\mathrm{H}_{2} \mathrm{O}_{2}$ (Figure 2, Figure 3), yet loss of an enzyme involved in its biosynthesis, Trm1 [35,36], did not confer $\mathrm{H}_{2} \mathrm{O}_{2}$ sensitivity (Figure 4). This behavior draws a comparison to mRNA, as it has been reported that many of the transcripts induced in response to a stress are not essential for viability during a challenge from that stress [37,38]. MMS sensitivity was identified in trm1, trm 4 and trm 9 mutants, the latter as shown previously [11], whose corresponding proteins synthesize $\mathrm{m}_{2}^{2} \mathrm{G}$, $\mathrm{m}^{5} \mathrm{C}$ and $\mathrm{mcm}^{5} \mathrm{U} / \mathrm{mcm}^{5} \mathrm{~s}^{2} \mathrm{U}$, respectively. However, these modifications were not strongly associated with MMS exposure in PCA (Figure 2, Figure 3). Somewhat surprisingly, loss of Trm1, Trm4, Trm7 and Trm9 conferred $\mathrm{NaAsO}_{2}$ sensitivity. These methyltransferases are responsible for $\mathrm{m}_{2}^{2} \mathrm{G}, \mathrm{m}^{5} \mathrm{C}, \mathrm{m}^{1} \mathrm{G}$ (position 37) and $\mathrm{mcm}{ }^{5} \mathrm{u} / \mathrm{mcm}^{5} \mathrm{~s}^{2} \mathrm{U}$, respectively, of which only $\mathrm{m}^{2} \mathrm{G}$ was found to vary significantly in PCA (Figure 3). For $\mathrm{NaOCl}$, only trm 4 was sensitive to exposure and the $\mathrm{m}^{5} \mathrm{C}$ product of $\mathrm{Trm} 4$ was not associated with $\mathrm{NaOCl}$ exposure (Figure 3). Again, this behavior parallels that of mRNA transcripts the levels of which do not change after exposure but that encode proteins important for viability after exposure [37,38].

\section{Potential mechanisms linking tRNA modifications and the stress response}

These results reveal a complex and dynamic control of tRNA modifications in cellular survival responses and suggest models for homeostasis of the modifications. One example involves modifications for which the biosynthetic mutant is sensitive to exposure but the modification level does not change in wild type cells following exposure (e.g., MMS exposure and $t r m 1 / \mathrm{m}^{2}{ }_{2} \mathrm{G}$, trm 4 / $\mathrm{m}^{5} \mathrm{C}$, trm $9 / \mathrm{mcm}^{5} \mathrm{U}$ or $\mathrm{mcm}^{5} \mathrm{~s}^{2} \mathrm{U}$; Figure 2, Figure 3, Figure 4). The simplest explanation here is that the modification change occurs in a single tRNA species and the change is masked by an inverse change in the level of the modification in the larger population of tRNA molecules. As noted in Table S4, both $\mathrm{m}^{2}{ }_{2} \mathrm{~g}$ and $\mathrm{m}^{5} \mathrm{C}$ occur in multiple tRNAs. A second explanation parallels the idea of both pre-existing mRNA and stressor-induced transcription during a stress response. We have observed stressinduced increases in the levels of several modifications required for the survival response (Figure 2, Figure 3; ref. [11]). However, other modifications may already exist on tRNA molecules involved in selective translation of stress response messages. In both cases, the modifications are absolutely required for survival, but some are already present in unstressed cells and others are induced. Finally, it is possible that a modification, though its level may not change, is required for the subsequent synthesis of other modifications that 


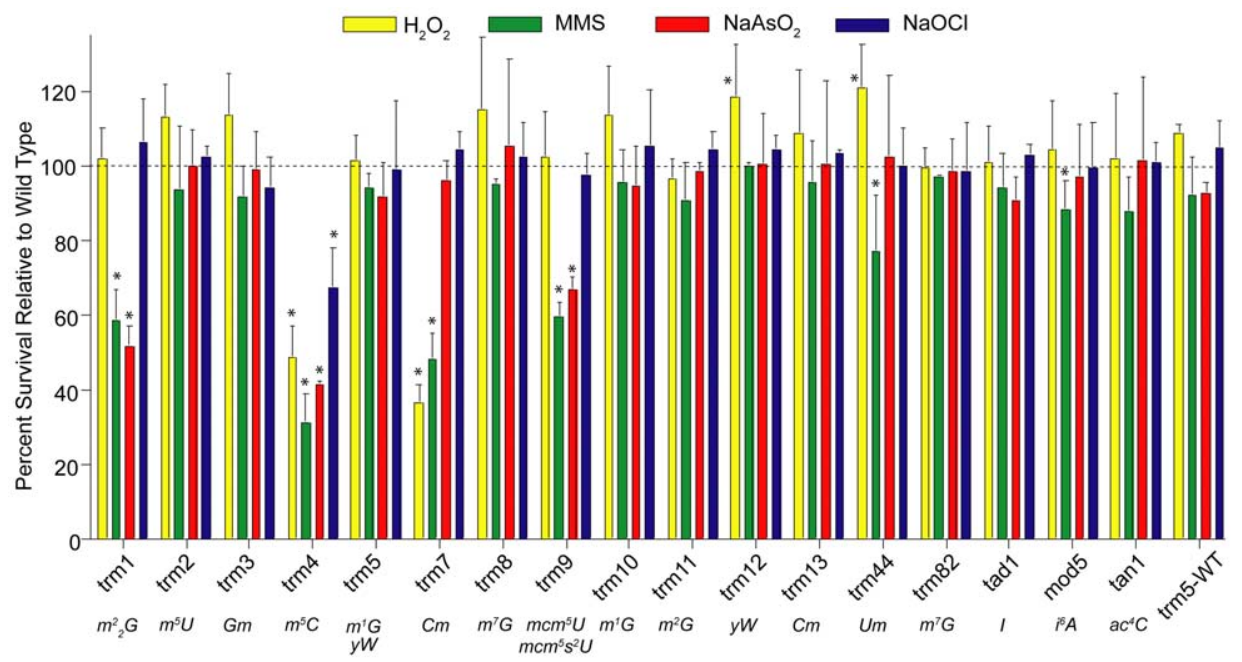

Figure 4. Phenotypic analysis of cytotoxicity induced by $\mathrm{MMS}, \mathrm{NaOCl}, \mathrm{H}_{2} \mathrm{O}_{2}$, and $\mathrm{NaAsO}_{2}$ in yeast mutants lacking trm tRNA methyltransferase and other modification genes. Data represent mean \pm SD for three biological replicates. Asterisks denote values statistically different from unexposed controls by Student's t-test, $p<0.05$. Associated RNA modifications are listed below each enzyme. doi:10.1371/journal.pgen.1001247.g004

are critical to the survival response. Such "cooperativity" is suggested by data from mod5-deficient cells, in which $i^{6} \mathrm{~A}$ decreases by $\sim 75$-fold while $\mathrm{D}$ is reduced by $\sim 2$-fold. The presence of $i^{6} \mathrm{~A}$ may signal downstream biosynthetic events, with deficiencies promoting a general reprogramming of tRNA. Similarly, cells deficient in Trm82, a subunit of $\mathrm{m}^{7} \mathrm{G}$ methyltransferase, had a $\sim 7$-fold reduction in $\mathrm{m}^{7} \mathrm{G}$ and a $>1.5$-fold increase in $\mathrm{m}^{3} \mathrm{C}$, $\mathrm{mcm}{ }^{5} \mathrm{U}, \mathrm{m}^{1} \mathrm{G}, \mathrm{m}^{2} \mathrm{G}, \mathrm{t}^{6} \mathrm{~A}, \mathrm{mcm}^{5} \mathrm{~s}^{2} \mathrm{U}$ and $\mathrm{m}_{2}{ }^{2} \mathrm{G}$ (Figure 5), which raises the possibility that Trm82 itself or $\mathrm{m}^{7} \mathrm{G}$ inhibits other tRNA modifying enzymes. With the caveat of possible increases in tRNA copy number, the $\sim 50 \%$ increase in these modifications suggests a pool of unmodified tRNA molecules, an observation supported by increases in $\mathrm{m}^{3} \mathrm{C}$ after exposure to $\mathrm{MMS}, \mathrm{mcm}^{5} \mathrm{U}$ after exposure to $\mathrm{NaOCl}$, and both $\mathrm{t}^{6} \mathrm{~A}$ and $\mathrm{m}_{2}{ }^{2} \mathrm{G}$ after exposure to $\mathrm{H}_{2} \mathrm{O}_{2}$ (Figure 2, Figure 3).

Cooperativity could also explain the case in which the level of a modification changes significantly following exposure yet the mutant strain is not sensitive to the exposure. For example, loss of trm 1 did not confer sensitivity to $\mathrm{H}_{2} \mathrm{O}_{2}$ but its product, $\mathrm{m}_{2}^{2} \mathrm{G}$, rose significantly with $\mathrm{H}_{2} \mathrm{O}_{2}$ exposure (Figure 2, Figure 3, Figure 4). The stress-induced change in $\mathrm{m}_{2}^{2} \mathrm{G}$ may be a response to a change occurring with another modification for which the mutant strain might be sensitive to the exposure. In support of this argument, $\mathrm{m}^{5} \mathrm{C}$ modifications increase along with $\mathrm{m}^{2}{ }_{2} \mathrm{G}$ after $\mathrm{H}_{2} \mathrm{O}_{2}$ exposure and deficiencies in the $\mathrm{m}^{5} \mathrm{C}$-producing methyltransferase Trm4 confer sensitivity to $\mathrm{H}_{2} \mathrm{O}_{2}$. Wohlgamuth-Benedum et al. have also demonstrated such cooperativity among RNA modifications in their observation of the negative regulation of wobble position Cto- $\mathrm{U}$ editing by thiolation of a $\mathrm{U}$ at position 33 outside the anticodon in T. brucei [39].

Finally, there is the case in which a modification decreases with exposure to a stressor and a deficiency in the enzyme responsible for that modification confers sensitivity, as in the case of $\mathrm{m}^{5} \mathrm{C}$, trm 4 and $\mathrm{NaOCl}$ (Figure 2, Figure 3, Figure 4). The population level of $\mathrm{m}^{5} \mathrm{C}$ may decrease with $\mathrm{NaOCl}$ exposure in spite of a protective increase in the level of $\mathrm{m}^{5} \mathrm{C}$ at some critical tRNA location. This may reflect a decrease in the transcription of tRNA substrates of Trm4 or the targeted degradation of specific tRNA species. It is important to note that biosynthetic redundancy, as in the case of Gm with Trm3 and Trm7, could mask any major changes in
tRNA modification levels that are associated with mutational loss of one enzyme (Figure 5), yet loss of one of the redundant enzymes can induce sensitivity, such as the case of $\mathrm{H}_{2} \mathrm{O}_{2}$ and $t r m 7$ (Figure 2, Figure 3, Figure 4). These observations lead to many questions

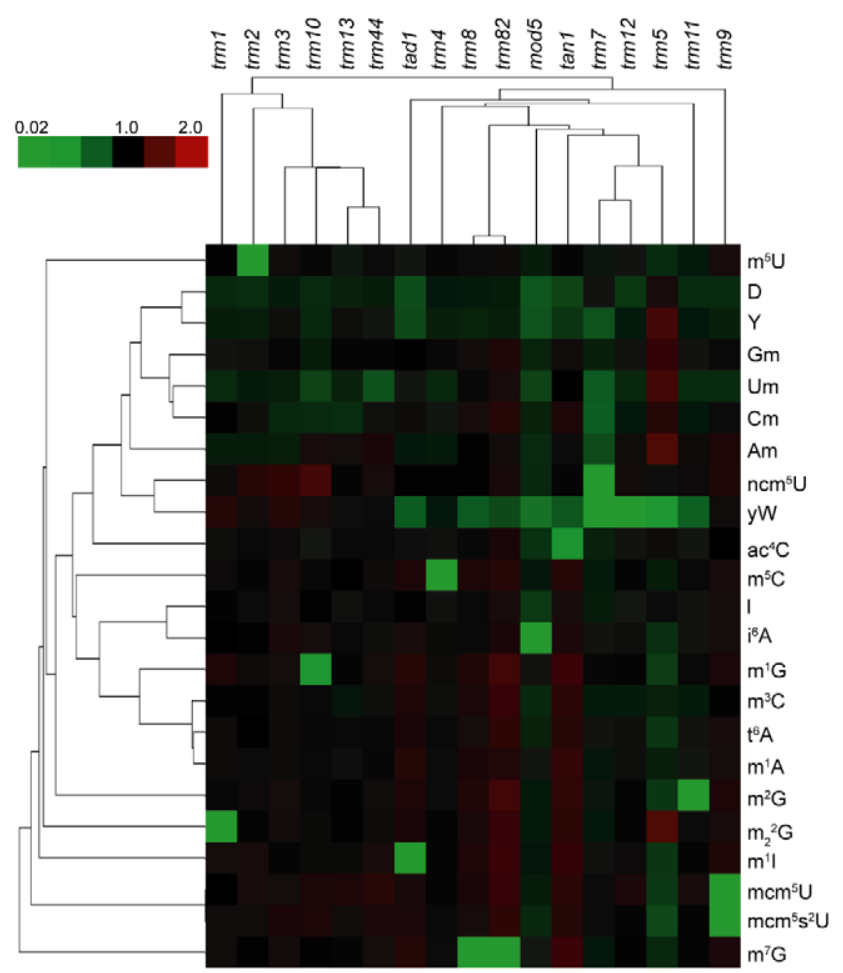

Figure 5. Cluster analysis visualization of changes in the relative levels of tRNA ribonucleoside modifications in mutants lacking ribonucleoside-modifying enzymes. The ratios of ribonucleoside levels from Table S5 were subjected to hierarchical cluster analysis. Red - increases; green - decreases. The top-left color bar indicates the range of fold-change values. doi:10.1371/journal.pgen.1001247.g005 
that obviously require more mechanistic study to define the precise role of tRNA modifications in cellular responses to stress.

One consistent feature that arose from our studies of modifications affected by or protecting against toxicant exposure was the frequent involvement of the wobble position, 34 (Tables $\mathrm{S} 4, \mathrm{~S} 6$ ). The correlation between the wobble modification and the importance of a corresponding enzyme after toxicant exposure is not surprising in light of recent observations of the critical role played by these modifications and anticodon loop ribonucleosides in translational fidelity and efficiency [4]. Controlled alteration of ribonucleoside structure at position 34 , and that at the conserved purine at position 37 , is proposed to allow reading of degenerate codons by modulating the structure of the anticodon domain to facilitate correct codon binding [4]. As the most frequently modified ribonucleosides, positions 34 and 37 also have the largest variety of modifications $[40,41]$, so it is reasonable that they would be extensively involved in translational control of the survival response. This is also consistent with our previous observation that mcm ${ }^{5} \mathrm{U}$ at the wobble position was critical to the translation of key protein synthesis and DNA damage response genes [11].

Perhaps more interesting is a potential role for putative nonanticodon loop ribonucleoside modifications in the survival response. For example, Trm44 is the $2^{\prime}-O$-methyltransferase in yeast responsible for formation of $2^{\prime}$-O-methyl-U $(\mathrm{Um})$, which occurs only at position 44 in yeast tRNA $[42,43]$. Loss of Trm 44 conferred sensitivity to $\mathrm{NaAsO}_{2}$ exposure. This observation suggests three possibilities: (1) that Trm44 synthesizes or influences the synthesis of modifications at other positions in tRNA; (2) that Um occurs in positions other than 44 (e.g., anticodon loop); or (3) that $\mathrm{Um}(44)$ plays a role in modulating translation in response to $\mathrm{NaAsO}_{2}$ exposure. Another example involves Trml and $\mathrm{m}_{2}^{2} \mathrm{G}$ at position 26. Current evidence suggests that $\mathrm{m}_{2}^{2} \mathrm{G}$ occurs only at position 26 in yeast tRNA [43] and that Trml is the methyltransferase responsible for its formation [44]. The fact that loss of Trml conferred sensitivity to MMS and $\mathrm{NaAsO}_{2}$ exposure and that $\mathrm{H}_{2} \mathrm{O}_{2}$ exposure increased the level of $\mathrm{m}^{2}{ }_{2} \mathrm{G}$ again suggest the three possibilities analogous to those for Trm44 and Um. Similar arguments can be made for Trm3 and $\mathrm{Gm}$ at position 18 with $\mathrm{NaOCl}$ exposure, for Trm 11 and $\mathrm{m}^{2} \mathrm{G}$ at position 10 with $\mathrm{NaOCl}$ and $\mathrm{NaAsO}_{2}$ exposure, and for Trm8/82 and $\mathrm{m}^{7} \mathrm{G}$ at position 46 with MMS exposure.

All of these observations point to participation of wobble and non-wobble RNA modifications in a complex and dynamic network of translational mechanisms in cellular responses. This expands the repertoire of translational control mechanisms, which includes recent discoveries about the effect of ribonucleoside modifications on tRNA stability [8,9]. In this model, cell stress leads to rapid degradation of specific tRNAs and subsequent effects on translational efficiency. Another similar stress response involves cleavage of cytoplasmic transfer RNAs by ribonucleases released during the stress [10]. One consequence of these degradation pathways would be to decrease the amount of modified ribonucleoside detected in our assay, which may explain some of our observations with the toxicant stresses. Our approach to quantifying tRNA modifications provides information only about population-level changes, so the observed changes could result from modification of existing tRNA molecules or changes in the number of tRNA copies. Of particular importance here is the observation by Phizicky and coworkers that loss of $\mathrm{m}^{7} \mathrm{G}$ at position 46 leads to degradation of specific tRNAs [9], which suggests that our observation of changes in the levels of RNA modifications could be amplified by both reduction in the activity of modifying enzymes and by tRNA degradation. On the other hand, one argument against large increases in tRNA copy number arises from recent observations of repressed tRNA transcription during S-phase and, of direct relevance to the present studies, during replication stress induced by MMS, hydroxyurea and likely other toxicants [45]. Finally, our findings may also parallel recent work on tRNA charging. Reactive oxygen species have been implicated as a methionine misacylation trigger and modification status could help promote these programmed changes to the genetic code [12]. As we are beginning to appreciate the precision and coordinated nature by which cells mount a regulated stress-response, it is most likely the observed changes in tRNA modification levels promote multiple biological responses.

\section{Novel biosynthetic pathways for tRNA modifications}

As recognized by several groups [19,20], the LC-MS/MS platform facilitates definition of biosynthetic pathways for RNA modifications. This is illustrated in Table S5, which contains ratios of the basal levels of tRNA modifications in yeast mutants lacking various tRNA modification enzymes compared to wild type yeast, and in a heat map visual depiction of these ratios in Figure 5. These data corroborate known substrate/enzyme pairs [43] and further demonstrate the highly quantitative nature of our approach. For example, the level of $\mathrm{m}^{1} \mathrm{I}$ drops to nearly undetectable levels with loss of Tadl, the adenosine deaminase producing the inosine precursor to $\mathrm{m}^{1} \mathrm{I}$ [46]. That a diploid heterozygous mutant of trm5, the product of which catalyzes $\mathcal{N}$ methylation of I [47], caused a $\sim 40 \%$ reduction in total $\mathrm{m}^{1} \mathrm{I}$ attests to the accuracy of our assay and demonstrate that gene dosage effects alter the level of tRNA modification. A similar $\sim 50 \%$ reduction in $\mathrm{yW}$ occurred in the trm 5 mutant due to the absence of the $\mathrm{m}^{1} \mathrm{G}(37)$ precursor to $\mathrm{yW}$ [47], while complete loss of Trm12, which methylates the 4-demethylwyosine precursor of $\mathrm{yW}$, made $\mathrm{yW}$ undetectable. Other pathways critical to $\mathrm{yW}$ are apparent in the smaller decreases in $\mathrm{yW}(0.3-$ to 0.5 -fold $)$ occurred in cells deficient in other enzymes (Trm8, Trm82, Tad1, Mod5, Tan1, Trm11, Trm5; Figure 5, Table S5).

The data in Figure 5 also reveal several novel observations. Pintard et al. observed that Trm7 catalyzes 2'-O-methylation of G and $\mathrm{C}$ nucleosides at positions 32 and 34, but they could not detect the $\mathrm{ncm}^{5} \mathrm{Um}$ product of $2^{\prime}-O$-methylation of $n \mathrm{~cm}^{5} \mathrm{U}$ [34]. While we could only tentatively identify $\mathrm{ncm}^{5} \mathrm{Um}$, we observed a quantifiable signal for a species with the correct molecular transition for $\mathrm{ncm}^{5} \mathrm{Um}$ and observed that loss of Trm7 led to a lowering of putative $\mathrm{ncm}^{5} \mathrm{Um}$ to undetectable levels (Figure 5, Table S5). This supports their prediction that Trm7 catalyzes formation of $\mathrm{ncm}^{5} \mathrm{Um}$ in yeast.

Another example involves the formation of Um. While Trm44 catalyzes synthesis of $\mathrm{Um}$ at position 44 in tRNA(ser) [42], analysis of trm mutants in Figure 5 and Table S5 suggests a redundancy in methyltransferase activity capable of 2'-O-methylation of $\mathrm{U}(44)$, including Trm7, which methylates $\mathrm{U}$ at positions 32 and 34 [34], and Trm 13 methylation of $\mathrm{C}$ and $\mathrm{A}$ at position 4 in several yeast tRNAs. Cells lacking Trm44, Trm7 or Trm13 have 53\%, 50\% and $76 \%$ of wild type levels of Um, respectively. More striking evidence for this redundancy arises in correlation analysis that revealed a strong covariance in the levels of tRNA modifications in cells lacking either Trm 44 or Trm 13 (Table S7; $\mathrm{C}=0.87$ ). This correlation ranks second highest in our analysis behind the two subunits of the $\mathrm{m}^{7} \mathrm{G}$ methyltransferase (Trm8 and Trm82; $\mathrm{C}=0.95$ ), which suggests possible functional redundancy for Trm44 and Trm13, with broader substrate specificities for either or both enzymes.

In summary, a quantitative bioanalytical approach to the study of tRNA modifications has revealed several novel biosynthetic pathways for RNA modifications and has led to the discovery of 
signature changes in the spectrum of tRNA modifications in the damage response to different toxicant exposures. The results support a general model of dynamic control of tRNA modifications in cellular response pathways and add to the growing repertoire of mechanisms controlling translational responses in cells [8-10,13]. Further, these cellular response mechanisms almost certainly involve parallel changes in spectrum of ribonucleoside modifications in rRNA and perhaps other RNA species.

\section{Materials and Methods}

\section{Materials}

All chemicals and reagents were of the highest purity available and were used without further purification. 2'-O-Methyluridine $(\mathrm{Um})$, pseudouridine $(\mathrm{Y}), \mathrm{N}^{1}$-methyladenosine $\left(\mathrm{m}^{1} \mathrm{~A}\right), \mathrm{N}^{2}, \mathrm{~N}^{2}$ dimethylguanosine $\left(\mathrm{m}_{2}^{2} \mathrm{G}\right)$, and $2^{\prime}$-O-methylguanosine $(\mathrm{Gm})$ were purchased from Berry and Associates (Dexter, MI). N ${ }^{6}$-Threonylcarbamoyladenosine $\left(t^{6} \mathrm{~A}\right)$ was purchased from Biolog (Bremen, Germany). $\mathrm{N}^{6}$-Isopentenyladenosine $\left(\mathrm{i}^{6} \mathrm{~A}\right)$ was purchased from International Laboratory LLC (San Bruno, CA). 2'-O-Methyladenosine (Am), $\mathrm{N}^{4}$-acetylcytidine $\left(\mathrm{ac}^{4} \mathrm{C}\right), 5$-methyluridine $\left(\mathrm{m}^{5} \mathrm{U}\right)$, inosine (I), 2-methylguanosine $\left(\mathrm{m}^{2} \mathrm{G}\right), \mathrm{N}^{7}$-methylguanosine $\left(\mathrm{m}^{7} \mathrm{G}\right)$, 2'-O-methylcytidine $(\mathrm{Cm}), 3$-methylcytidine $\left(\mathrm{m}^{3} \mathrm{C}\right), 5$-methylcytidine $\left(\mathrm{m}^{5} \mathrm{C}\right)$, alkaline phosphatase, lyticase, RNase $\mathrm{A}$, ammonium acetate, geneticine and desferrioxamine were purchased from Sigma Chemical Co. (St. Louis, MO). Nuclease P1 was purchased from Roche Diagnostic Corp. (Indianapolis, IN). Phosphodiesterase I was purchased from USB (Cleveland, OH). PureLink miRNA Isolation Kits were purchased from Invitrogen (Carlsbad, CA). Acetonitrile and HPLC-grade water were purchased from Mallinckrodt Baker (Phillipsburg, NJ). All strains of $S$. cerevisiae BY4741 were purchased from American Type Culture Collections (Manassas, VA).

\section{Exposure of S. cerevisiae}

Cultures of $S$. cerevisiae BY4741 were grown to mid-log phase followed by addition of toxicants to the noted final concentrations (cytotoxicity of $\sim 20 \%, 50 \%$ and $80 \%$ ): $\mathrm{H}_{2} \mathrm{O}_{2}, 2,5$ or $12 \mathrm{mM}$; MMS, 6, 12 or $24 \mathrm{mM}$; $\mathrm{NaAsO}_{2}, 20,40$ or $60 \mathrm{mM}$; NaOCl, 3.2, 4.0 or $4.8 \mathrm{mM}$. The sensitivity of the following mutant strains to toxicant exposure was also determined (doses producing $\sim 80 \%$ cytotoxicity in wild-type: $12 \mathrm{mM} \mathrm{H}_{2} \mathrm{O}_{2}, 24 \mathrm{mM} \mathrm{MMS,} 60 \mathrm{mM}$ $\mathrm{NaAsO}_{2}$, or $\left.4.8 \mathrm{mM} \mathrm{NaOCl}\right):$ trm 1, trm2, trm3, trm4, trm 7, trm8, trm9, trm10, trm11, trm12, trm13, trm44, trm82, tad1, $\bmod 5$, and tan1. Since trm 5 is essential, a diploid strain (GBYI) lacking one copy of trm 5 was used. After a $1 \mathrm{~h}$, cells were collected and viability determined by plating.

\section{tRNA isolation}

Following lyticase treatment (50 units) in the presence of deaminase inhibitors $(5 \mu \mathrm{g} / \mathrm{ml}$ coformycin, $50 \mu \mathrm{g} / \mathrm{ml}$ tetrahydrouridine) and antioxidants $(0.1 \mathrm{mM}$ desferrioxamine, $0.1 \mathrm{mM}$ butylated hydroxytoluene), tRNA-containing small RNA species were isolated (Invitrogen PureLink miRNA kit) and the tRNA quantified (Agilent Series 2100 Bioanalyzer).

\section{Quantification of cytoplasmic tRNA modifications}

Following addition of deaminase inhibitors, antioxidants and $\left[{ }^{15} \mathrm{~N}_{5}\right.$-2-deoxyadenosine internal standard $(6 \mathrm{pmol})$, tRNA $(6 \mu \mathrm{g})$ in $30 \mathrm{mM}$ sodium acetate and $2 \mathrm{mM} \mathrm{ZnCl}_{2}(\mathrm{pH} 6.8)$ was hydrolyzed with nuclease $\mathrm{P} 1(1 \mathrm{U})$ and RNase A $(5 \mathrm{U})$ for $3 \mathrm{~h}$ at $37^{\circ} \mathrm{C}$ and dephosphorylated with alkaline phosphatase (10 U) and phosphodiesterase $\mathrm{I}(0.5 \mathrm{U})$ for $1 \mathrm{~h}$ at $37^{\circ} \mathrm{C}$ following addition of acetate buffer to $30 \mathrm{mM}$, pH 7.8. Proteins were removed by filtration (Microcon YM-10). Ribonucleosides were resolved with a Thermo Scientific Hypersil GOLD aQ reverse-phase column $(150 \times 2.1 \mathrm{~mm}, 3 \mu \mathrm{m}$ particle size $)$ eluted with the following gradient of acetonitrile in $8 \mathrm{mM}$ ammonium acetate at a flow rate of $0.3 \mathrm{ml} / \mathrm{min}$ and $36^{\circ} \mathrm{C}$ : $0-18 \mathrm{~min}, 1-2 \%$; $18-23 \mathrm{~min}, 2 \%$; 23-28 min, 2-7\%; 28-30 min, 7\%; 30-31 min, 7-100\%; 31$41 \mathrm{~min}, 100 \%$. The HPLC column was coupled to an Agilent 6410 Triple Quadrupole LC/MS mass spectrometer with an electrospray ionization source where it was operated in positive ion mode with the following parameters for voltages and source gas: gas temperature, $350^{\circ} \mathrm{C}$; gas flow, $10 \mathrm{l} / \mathrm{min}$; nebulizer, $20 \mathrm{psi}$; and capillary voltage, $3500 \mathrm{~V}$. The first and third quadrupoles $(\mathrm{Q} 1$ and Q3) were fixed to unit resolution and the modifications were quantified by pre-determined molecular transitions. Q1 was set to transmit the parent ribonucleoside ions and Q3 was set to monitor the deglycosylated product ions, except for $\mathrm{Y}$ for which the stable G-C glycosidic bond led to fragmentation of the ribose ring; we used the $m / z 125$ ion for quantification $[48,49]$. The dwell time for each ribonucleoside was $200 \mathrm{~ms}$. The retention time, $\mathrm{m} / \mathrm{z}$ of the transmitted parent ion, $\mathrm{m} / \mathrm{z}$ of the monitored product ion, fragmentor voltage, and collision energy of each modified nucleoside and ${ }^{15} \mathrm{~N}$-labeled internal standard are as follow: $\mathrm{D}$, $1.9 \mathrm{~min}, \mathrm{~m} / z 247 \rightarrow 115,80 \mathrm{~V}, 5 \mathrm{~V}$; Y, $2.5 \mathrm{~min}, \mathrm{~m} / z \quad 245 \rightarrow 125$, $80 \mathrm{~V}, 10 \mathrm{~V} ; \mathrm{m}^{5} \mathrm{C}, 3.3 \mathrm{~min}, \mathrm{~m} / \mathrm{z} 258 \rightarrow 126,80 \mathrm{~V}, 8 \mathrm{~V}$; Cm, $3.6 \mathrm{~min}, \mathrm{~m} / \mathrm{z} \quad 258 \rightarrow 112, \quad 80 \mathrm{~V}, \quad 8 \mathrm{~V} ; \mathrm{m}^{5} \mathrm{U}, 4.2 \mathrm{~min}, \mathrm{~m} / z$ $259 \rightarrow 127,80 \mathrm{~V}, 7 \mathrm{~V} ; \mathrm{ncm}^{5} \mathrm{U}, 4.3 \mathrm{~min}, \mathrm{~m} / z \quad 302 \rightarrow 170,90 \mathrm{~V}$, $7 \mathrm{~V}$; ac ${ }^{4} \mathrm{C}, 4.4 \mathrm{~min}, \mathrm{~m} / z 286 \rightarrow 154,80 \mathrm{~V}, 6 \mathrm{~V} ; \mathrm{m}^{3} \mathrm{C}, 4.4 \mathrm{~min}$, $\mathrm{m} / z 258 \rightarrow 126,80 \mathrm{~V}, 8 \mathrm{~V} ; \mathrm{ncm}^{5} \mathrm{Um}, 5.5 \mathrm{~min}, \mathrm{~m} / z \quad 316 \rightarrow 170$, $90 \mathrm{~V}, 7 \mathrm{~V}$; Um, $5.1 \mathrm{~min}, \mathrm{~m} / z \quad 259 \rightarrow 113,80 \mathrm{~V}, 7 \mathrm{~V} ; \mathrm{m}^{7} \mathrm{G}$, $5.1 \mathrm{~min}, \quad m / z \quad 298 \rightarrow 166,90 \mathrm{~V}, 10 \mathrm{~V} ; \mathrm{m}^{1} \mathrm{~A}, 5.7 \mathrm{~min}, \mathrm{~m} / \mathrm{z}$ $282 \rightarrow 150, \quad 100 \mathrm{~V}, \quad 16 \mathrm{~V} ; \mathrm{mcm}^{5} \mathrm{U}, 6.4 \mathrm{~min}, \mathrm{~m} / z \quad 317 \rightarrow 185$, $90 \mathrm{~V}, 7 \mathrm{~V} ; \mathrm{m}^{1} \mathrm{I}, 7.3 \mathrm{~min}, \mathrm{~m} / z \quad 283 \rightarrow 151,80 \mathrm{~V}, 10 \mathrm{~V} ; \mathrm{Gm}$, $8.0 \mathrm{~min}, \mathrm{~m} / \mathrm{z} \quad 298 \rightarrow 152, \quad 80 \mathrm{~V}, \quad 7 \mathrm{~V} ; \mathrm{m}^{1} \mathrm{G}, 8.3 \mathrm{~min}, \mathrm{~m} / \mathrm{z}$ $298 \rightarrow 166,90 \mathrm{~V}, 10 \mathrm{~V} ; \mathrm{m}^{2} \mathrm{G}, 9.4 \mathrm{~min}, \mathrm{~m} / z \quad 298 \rightarrow 166,90 \mathrm{~V}$, $10 \mathrm{~V} ; \quad \mathrm{I}, 10.9 \mathrm{~min}, \mathrm{~m} / z \quad 269 \rightarrow 137,80 \mathrm{~V}, 10 \mathrm{~V} ; \mathrm{mcm}^{5} \mathrm{~s}^{2} \mathrm{U}$, $14.2 \mathrm{~min}, \mathrm{~m} / \mathrm{z} 333 \rightarrow 201,90 \mathrm{~V}, 7 \mathrm{~V} ;\left[{ }^{15} \mathrm{~N}\right]_{5}-\mathrm{dA}, 14.4 \mathrm{~min}, \mathrm{~m} / \mathrm{z}$ $257 \rightarrow 141,90 \mathrm{~V}, 10 \mathrm{~V} ; \mathrm{m}_{2}{ }_{2} \mathrm{G}, 15.9 \mathrm{~min}, \mathrm{~m} / z 312 \rightarrow 180,100 \mathrm{~V}$, $8 \mathrm{~V} ; \mathrm{t}^{6} \mathrm{~A}, 17.2 \mathrm{~min}, \mathrm{~m} / z 413 \rightarrow 281,100 \mathrm{~V}, 8 \mathrm{~V} ; \mathrm{Am}, 19 \mathrm{~min}, \mathrm{~m} / z$ $282 \rightarrow 136,100 \mathrm{~V}, 15 \mathrm{~V} ; \mathrm{yW}, 34.2 \mathrm{~min}, \mathrm{~m} / z 509 \rightarrow 377,80 \mathrm{~V}, 5 \mathrm{~V}$, and $\mathrm{i}^{6} \mathrm{~A}, 34.4 \mathrm{~min}, \mathrm{~m} / \mathrm{z} \quad 336 \rightarrow 204,100 \mathrm{~V}, 17 \mathrm{~V}$. The mass spectrometer monitored ions with the molecular transitions of $\mathrm{D}$, $\mathrm{Y}, \mathrm{m}^{5} \mathrm{C}$, and $\mathrm{Cm}$ from 1 to $4 \mathrm{~min}$; molecular transitions of $\mathrm{m}^{5} \mathrm{U}$, $n c{ }^{5} \mathrm{U}, \mathrm{ac}^{4} \mathrm{C}, \mathrm{m}^{3} \mathrm{C}, \mathrm{ncm}{ }^{5} \mathrm{Um}, \mathrm{Um}, \mathrm{m}^{7} \mathrm{G}, \mathrm{m}^{1} \mathrm{~A}$, and $\mathrm{mcm}^{5} \mathrm{U}$ from 4 to $7 \mathrm{~min}$; molecular transitions of $\mathrm{m}^{1} \mathrm{I}, \mathrm{Gm}, \mathrm{m}^{1} \mathrm{G}$, and $\mathrm{m}^{2} \mathrm{G}$ from 7 to $10 \mathrm{~min}$; molecular transitions of $\mathrm{I}, \mathrm{mcm}^{5} \mathrm{~s}^{2} \mathrm{U},\left[{ }^{15} \mathrm{~N}\right]_{5}-\mathrm{dA}, \mathrm{m}_{2}^{2} \mathrm{G}$, $\mathrm{t}^{6} \mathrm{~A}$, and Am from 10 to $30 \mathrm{~min}$; molecular transitions of $\mathrm{yW}$ and $i^{6} \mathrm{~A}$ from 30 to $40 \mathrm{~min}$. The identities of individual ribonucleosides were established by comparison to commercially available synthetic standards, high mass accuracy mass spectrometry, fragmentation patterns generated by collision-induced dissociation (CID) in a quadrupole time-of-flight mass spectrometer (QTOF) or $\mathrm{MS}^{\mathrm{n}}$ analysis by ion trap mass spectrometry, with comparison to literature data (e.g., ref. [48]).

\section{Quantification of $\mathrm{m}^{7} \mathrm{G}$ in control and MMS-treated yeast}

To assess the direct and indirect effects of MMS on levels of methylated ribonucleosides, the absolute levels of $\mathrm{m}^{7} \mathrm{G}$ were quantified in small RNA hydrolysates isolated from MMS-exposed and unexposed mutant and wild type strains of yeast by the LC-MS/ MS method described above. Calibration curves were generated by mixing variable amounts of $\mathrm{m}^{7} \mathrm{G}$ (final concentrations of $0,5,50,300$, 600,1000 , and $2000 \mathrm{nM}$ ) with a fixed concentration of $\left[{ }^{15} \mathrm{~N}\right]_{5}-\mathrm{dA}$ $(40 \mathrm{nM})$. A volume of $10 \mu \mathrm{l}$ of each solution was analyzed with the LC-MS/MS system described earlier. 


\section{Statistical analysis of changes in the levels of tRNA modifications}

Differences in the levels of ribonucleosides in exposed versus unexposed and in mutant versus wild-type yeast were analyzed by Student's t-test. Hierarchical clustering analyses were performed using Cluster 3.0. Data were transformed to $\log _{2}$ ratios of modification levels in treated cells relative to unexposed controls. Clustering was carried out using the centroid linkage algorithm based on the distance between each dataset measured using the Pearson correlation, with heat map representations produced using Java Treeview. Principal component analysis was performed using XLStat (Addinsoft SARL, Paris, France), with a Pearson correlation matrix consisting of data that were mean-centered and normalized to the standard deviation. Correlation analysis was used to assess the degree of covariance among the various sets of fold-change values for each mutant (Table S5), with correlation coefficients calculated using Excel (Microsoft).

\section{Supporting Information}

Figure S1 Mass spectrometer signal intensities for tRNA ribonucleoside modifications. Small RNA isolates containing tRNA (85\%) were enzymatically hydrolyzed and quantities ranging from 0.1 to $2 \mu \mathrm{g}$ were analyzed by LC-MS/MS. Mass spectrometer signal intensities were determined for 23 of 25 modified ribonucleosides from yeast tRNA and plotted against total tRNA. Data represent mean \pm SD for three analyses of the same sample.

Found at: doi:10.1371/journal.pgen.1001247.s001 (1.76 MB TIF)

Figure S2 Cytotoxicity dose-response studies with $S$. cerevisiae exposed to MMS, $\mathrm{H}_{2} \mathrm{O}_{2}, \mathrm{NaAsO}_{2}$ and $\mathrm{NaOCl}$. Data represent mean \pm SD for three biological replicates. The dotted line marks the $80 \%$ survival level.

Found at: doi:10.1371/journal.pgen.1001247.s002 (1.18 MB TIF)

Figure S3 Quantification of absolute level of $\mathrm{m}^{7} \mathrm{G}$ in different strains of yeast with or without MMS-exposure. Data represent mean \pm SD for three biological replicates.

Found at: doi:10.1371/journal.pgen.1001247.s003 (2.88 MB TIF)

Table S1 Normalized mass spectrometer signal intensities for tRNA modifications in $S$. cerevisiae treated with four toxicants. Data represent mean $\pm \mathrm{SD}$ for $\mathrm{N}=3$, with Student's t-test relative to control values.

Found at: doi:10.1371/journal.pgen.1001247.s004 (0.99 MB PDF)

Table S2 Fold-change values for $S$. cerevisiae tRNA modifications in treated cells relative to untreated controls. * Based on data from Table S1.

Found at: doi:10.1371/journal.pgen.1001247.s005 (0.07 MB PDF)

Table S3 Contribution of each agent to variance in principal component analysis.

Found at: doi:10.1371/journal.pgen.1001247.s006 (0.03 MB PDF)

Table S4 Relationships between conserved locations of tRNA ribonucleosides that are altered by exposure or that confer resistance to cytotoxicity in $S$. cerevisiae.

Found at: doi:10.1371/journal.pgen.1001247.s007 (0.09 MB PDF)

Table S5 Ratios of the levels of tRNA modifications in mutant strains relative to wild type $S$. cerevisiae. Underlined: Mutant was determined to be significantly different from wild type by Student's t-test with $\mathrm{P}<0.05$; Yellow: ratios $<0.02$ (values of 0.00001 indicate undetectable ribonucleosides in the mutant strains); Green: ratios $<0.6$; Red: ratios $>1.5$.

Found at: doi:10.1371/journal.pgen.1001247.s008 (0.65 MB PDF)

Table S6 Locations of tRNA ribonucleosides affected by exposure to toxicants and critical to surviving toxicant exposure. Found at: doi:10.1371/journal.pgen.1001247.s009 (0.04 MB PDF)

Table S7 Correlation coefficients between tRNA modification profiles for each mutant. Coefficients above 0.8 are shaded red and those between 0.5 and 0.8 are shaded pink.

Found at: doi:10.1371/journal.pgen.1001247.s010 (0.67 MB PDF)

\section{Acknowledgments}

We thank Dr. John Wishnok for assistance with mass spectrometry, which was performed in the Bioanalytical Facilities Core of the MIT Center for Environmental Health Science.

\section{Author Contributions}

Conceived and designed the experiments: CTYC PCD TJB. Performed the experiments: CTYC MSD. Analyzed the data: CTYC MD MSD KT PCD TJB. Contributed reagents/materials/analysis tools: CTYC MD TJB. Wrote the paper: CTYG MD MSD KT PGD TJB

\section{References}

1. Alberts B (2008) Molecular biology of the cell, 5th edition. Extended version. New York: Garland Science.

2. Crain PF, Rozenski J, McCloskey JA (1999) The RNA modification database.

3. Czerwoniec A, Dunin-Horkawicz S, Purta E, Kaminska KH, Kasprzak JM, et al. (2009) MODOMICS: a database of RNA modification pathways. 2008 update. Nucleic Acids Res 37: D118-121.

4. Agris PF, Vendeix FA, Graham WD (2007) tRNA's wobble decoding of the genome: 40 years of modification. J Mol Biol 366: 1-13.

5. Yarian C, Townsend H, Czestkowski W, Sochacka E, Malkiewicz AJ, et al. (2002) Accurate translation of the genetic code depends on tRNA modified nucleosides. J Biol Chem 277: 16391-16395.

6. Urbonavicius J, Qian Q Durand JM, Hagervall TG, Bjork GR (2001) Improvement of reading frame maintenance is a common function for several tRNA modifications. EMBO J 20: 4863-4873.

7. Bjork GR, Durand JM, Hagervall TG, Leipuviene R, Lundgren HK, et al. (1999) Transfer RNA modification: influence on translational frameshifting and metabolism. FEBS Lett 452: 47-51.

8. Motorin Y, Helm M (2010) tRNA stabilization by modified nucleotides. Biochemistry 49: 4934-4944.

9. Alexandrov A, Chernyakov I, Gu W, Hiley SL, Hughes TR, et al. (2006) Rapid tRNA decay can result from lack of nonessential modifications. Mol Cell 21: 87-96.

10. Thompson DM, Parker R (2009) Stressing out over tRNA cleavage. Cell 138: 215-219.
11. Begley U, Dyavaiah M, Patil A, Rooney JP, Direnzo D, et al. (2007) Trm9catalyzed tRNA modifications link translation to the DNA damage response. Mol Cell 28: 860-870.

12. Netzer N, Goodenbour JM, David A, Dittmar KA, Jones RB, et al. (2009) Innate immune and chemically triggered oxidative stress modifies translational fidelity. Nature 462: 522-526.

13. Emilsson V, Naslund AK, Kurland CG (1992) Thiolation of transfer RNA in Escherichia coli varies with growth rate. Nucleic Acids Res 20: 4499-4505.

14. Begley TJ, Rosenbach AS, Ideker T, Samson LD (2004) Hot spots for modulating toxicity identified by genomic phenotyping and localization mapping. Mol Cell 16: 117-125.

15. Bennett CB, Lewis LK, Karthikeyan G, Lobachev KS, Jin YH, et al. (2001) Genes required for ionizing radiation resistance in yeast. Nat Genet 29: $426-434$.

16. Rooney JP, George AD, Patil A, Begley U, Bessette E, et al. (2008) Systems based mapping demonstrates that recovery from alkylation damage requires DNA repair, RNA processing, and translation associated networks. Genomics 10: 524 .

17. Kalhor HR, Clarke S (2003) Novel methyltransferase for modified uridine residues at the wobble position of tRNA. Mol Cell Biol 23: 9283-9292.

18. Weissenbach J, Dirheimer G (1978) Pairing properties of the methylester of 5carboxymethyl uridine in the wobble position of yeast tRNA3Arg. Biochim Biophys Acta 518: 530-534. 
19. Suzuki T, Ikeuchi Y, Noma A, Sakaguchi Y (2007) Mass spectrometric identification and characterization of RNA-modifying enzymes. Methods Enzymol 425: 211-229.

20. Meng Z, Limbach PA (2006) Mass spectrometry of RNA: linking the genome to the proteome. Brief Funct Genomic Proteomic 5: 87-95.

21. Morris JC (1966) The acid ionization constant of HOCl. J Phys Chem 70: 3798-3805.

22. Zhou X, Arita A, Ellen TP, Liu X, Bai J, et al. (2009) A genome-wide screen in Saccharomyces cerevisiae reveals pathways affected by arsenic toxicity. Genomics 94 : 294-307.

23. Fry RC, Begley TJ, Samson LD (2005) Genome-wide responses to DNAdamaging agents. Annu Rev Microbiol 59: 357-377.

24. Singer B, Grunberger D (1983) Molecular Biology of Mutagens and Carcinogens. New York: Plenum.

25. Loechler EL (1994) A violation of the Swain-Scott principle, and not SN1 versus SN2 reaction mechanisms, explains why carcinogenic alkylating agents can form different proportions of adducts at oxygen versus nitrogen in DNA. Chem Res Toxicol 7: 277-280.

26. Hampton MB, Kettle AJ, Winterbourn CC (1998) Inside the neutrophil phagosome: oxidants, myeloperoxidase, and bacterial killing. Blood 92: 3007-3017.

27. Winterbourn CC, Kettle AJ (2000) Biomarkers of myeloperoxidase-derived hypochlorous acid. Free Radic Biol Med 29: 403-409.

28. Ohshima H, Tatemichi M, Sawa T (2003) Chemical basis of inflammationinduced carcinogenesis. Arch Biochem Biophys 417: 3-11.

29. Suzuki T, Masuda M, Friesen MD, Fenet B, Ohshima H (2002) Novel products generated from 2'-deoxyguanosine by hypochlorous acid or a myeloperoxidase$\mathrm{H}_{2} \mathrm{O}_{2}-\mathrm{Cl}^{-}$-system: identification of diimino-imidazole and amino-imidazole nucleosides. Nucleic Acids Res 30: 2555-2564.

30. Higashikawa Y, Kazui Y, Suzuki S, Ohtsuru O (2008) Arsenic speciation of arsine-exposed blood samples by high-performance liquid chromatographyinductively coupled plasma mass spectrometry and As-adduct, a possible indicator of $\mathrm{AsH}_{3}$ exposure. J Anal Toxicol 32: 344-348.

31. Kitchin KT (2001) Recent advances in arsenic carcinogenesis: modes of action, animal model systems, and methylated arsenic metabolites. Toxicol Appl Pharmacol 172: 249-261.

32. Hei TK, Filipic M (2004) Role of oxidative damage in the genotoxicity of arsenic. Free Radic Biol Med 37: 574-581.

33. Motorin Y, Grosjean H (1999) Multisite-specific tRNA:m5C-methyltransferase $(\operatorname{Trm} 4)$ in yeast Saccharomyces cerevisiae: identification of the gene and substrate specificity of the enzyme. RNA 5: 1105-1118.

34. Pintard L, Lecointe F, Bujnicki JM, Bonnerot C, Grosjean H, et al. (2002) Trm7p catalyses the formation of two 2'-O-methylriboses in yeast tRNA anticodon loop. EMBO J 21: 1811-1820.

35. El Yacoubi B, Lyons B, Cruz Y, Reddy R, Nordin B, et al. (2009) The universal YrdC/Sua5 family is required for the formation of threonylcarbamoyladenosine in tRNA. Nucleic Acids Res 37: 2894-2909.
36. Ellis SR, Morales MJ, Li JM, Hopper AK, Martin NC (1986) Isolation and characterization of the TRM1 locus, a gene essential for the N2,N2dimethylguanosine modification of both mitochondrial and cytoplasmic tRNA in Saccharomyces cerevisiae. J Biol Chem 261: 9703-9709.

37. Begley TJ, Rosenbach AS, Ideker T, Samson LD (2002) Damage recovery pathways in Saccharomyces cerevisiae revealed by genomic phenotyping and interactome mapping. Mol Cancer Res 1: 103-112.

38. Birrell GW, Brown JA, Wu HI, Giaever G, Chu AM, et al. (2002) Transcriptional response of Saccharomyces cerevisiae to DNA-damaging agents does not identify the genes that protect against these agents. Proc Natl Acad Sci USA 99: $8778-8783$.

39. Wohlgamuth-Benedum JM, Rubio MA, Paris Z, Long S, Poliak P, et al. (2009) Thiolation controls cytoplasmic tRNA stability and acts as a negative determinant for tRNA editing in mitochondria. J Biol Chem 284: 23947-23953.

40. Agris PF (1996) The importance of being modified: roles of modified nucleosides and $\mathrm{Mg}^{2+}$ in RNA structure and function. Prog Nucleic Acid Res Mol Biol 53: 79-129.

41. Sprinzl M, Vassilenko KS (2005) Compilation of tRNA sequences and sequences of tRNA genes. Nucleic Acids Res 33: D139-140.

42. Kotelawala L, Grayhack EJ, Phizicky EM (2008) Identification of yeast tRNA Um44 2'-O-methyltransferase (Trm44) and demonstration of a Trm44 role in sustaining levels of specific tRNASer species. RNA 14: 158-169.

43. Johansson MJO, Bystrom AS (2005) Transfer RNA modification and modifying enzymes in Saccharomyces cerevisae. In: Grosjean H, ed. Topics in current genetics: Fine-tuning of RNA functions by modification and editing. Berlin; New York: Springer. pp 87-120.

44. Ellis SR, Morales MJ, Li JM, Hopper AK, Martin NC (1986) Isolation and characterization of the TRM1 locus, a gene essential for the $\mathrm{N}^{2}, \mathrm{~N}^{2}$ dimethylguanosine modification of both mitochondrial and cytoplasmic tRNA in Saccharomyces cerevisiae. J Biol Chem 261: 9703-9709.

45. Nguyen VC, Clelland BW, Hockman DJ, Kujat-Choy SL, Mewhort HE, et al. (2010) Replication stress checkpoint signaling controls tRNA gene transcription. Nat Struct Mol Biol 17: 976-981.

46. Gerber A, Grosjean H, Melcher T, Keller W (1998) Tadlp, a yeast tRNAspecific adenosine deaminase, is related to the mammalian pre-mRNA editing enzymes ADAR1 and ADAR2. Embo J 17: 4780-4789.

47. Björk GR, Jacobsson K, Nilsson K, Johansson MJO, Byström AS, et al. (2001) A primordial tRNA modification required for the evolution of life? EMBO J 20 231-239.

48. Pomerantz SC, McCloskey JA (1990) Analysis of RNA hydrolyzates by liquid chromatography-mass spectrometry. Methods Enzymol 193: 796-824.

49. Dudley E, Tuytten R, Bond A, Lemiere F, Brenton AG, et al. (2005) Study of the mass spectrometric fragmentation of pseudouridine: comparison of fragmentation data obtained by matrix-assisted laser desorption/ionisation post-source decay, electrospray ion trap multistage mass spectrometry, and by a method utilising electrospray quadrupole time-of-flight tandem mass spectrometry and in-source fragmentation. Rapid Commun Mass Spectrom 19: 3075-3085. 